\title{
Evaluation of Tuna Meat Discoloration by Hunter Color Difference Scale
}

\author{
Yoshihiro Ochiai, ${ }^{* 1}$ Chau-Jen Chow, ${ }^{* 1,2}$ Shugo Watabe, ${ }^{* 1}$ \\ and Kanehisa Hashimoto*1
}

(Received September 28, 1987)

\begin{abstract}
Attempts were made to evaluate the discoloration of unfrozen tuna meat, and frozen and thawed ("frozen/thawed") tuna meat by Hunter tristimulus values ( $\mathbf{L}, \mathbf{a}$, and $\mathbf{b}$ ), as a substitute for the metmyoglobin (metMb) ratio (metMb\%). Correlation coefficient between metMb $\%$ and $\mathbf{a} / \mathbf{b}$ ratio was higher than that between metMb\% and a value. The coefficient was around -0.7 for bluefin and $-0.8 \sim-0.9$ for yellowfin tuna meat, suggesting that $\mathbf{a} / \mathbf{b}$ ratio can be used as a parameter to evaluate the discoloration of tuna meat.

$\mathbf{L}$ and $\mathbf{b}$ values were judged not to be useful parameters, since the former was remotely correlated with metMb\%, and the latter showed only a small change.
\end{abstract}

Bright red color is a commercially important factor for tuna meat because of public preference. Tuna meat discolors due mainly to autoxidation of oxymyoglobin (oxyMb) to metmyoglobin (metMb), and it is empirically known that frozen and thawed ("frozen/thawed") tuna meat discolors more rapidly than unfrozen meat. ${ }^{1)}$

Some reports deal with a direct measurement of the color of beef. Dean and Ball ${ }^{23}$ developed a reflectance spectrophotometric method to evaluate the total pigment and metMb formation in beef. Snyder ${ }^{3)}$ measured the color of beef by a Gardner color difference meter. However, no corresponding trials have so far been made for tuna meat.

Hunter color difference scale") has successfully been used to evaluate the color of egg yolk, ${ }^{\mathrm{s})}$ citrus juice, ${ }^{8)}$ and other agricultural products. ${ }^{7,8)}$ In the preceding paper, ${ }^{1)}$ we reported that frozen/ thawed tuna meat showed an accelerated autoxidation, as examined both by Hunter tristimulus values $(\mathbf{L}, \mathbf{a}$, and $\mathbf{b})$ and by metMb\%. We also mentioned that the increase of metMb\% was accompanied by a significant decrease of a value and a little increase of $\mathbf{L}$ and $\mathbf{b}$ values for both of bluefin tuna $\mathrm{Mb}$ and meat. In other words, discoloration of tuna meat could be accounted for by the decrease of redness and a little increase of whiteness and yellowness.

In the present paper, we statistically analyzed those and some other data for metMb\% and
Hunter tristimulus values of tuna meat, in an attempt to find a simple parameter for evaluation of tuna meat discoloration.

\section{Materials and Methods}

Fresh (unfrozen) specimens of bluefin Thunnus thynnus, yellowfin $T$. albacares, and bigeye tuna $T$. obesus were purchased, and the dorsal ordinary muscle was excised and used. In case of yellowfin tuna, ventral muscle was also used. The muscle was cut into slices of about $8 \times 3 \times 0.8 \mathrm{~cm}$. Half of them were stored in ice for up to 2 weeks, and analyzed for tristimulus values and metMb $\%$ at due time intervals. Another half of slices were stored at $-20^{\circ} \mathrm{C}$ for 2 weeks, thawed at $20^{\circ} \mathrm{C}$, and stored in ice, and similarly analyzed.

$\mathrm{Mb}$ was purified from the dark muscle of bluefin tuna by the method reported previously, ${ }^{0)}$ and was dissolved in $50 \mathrm{~mm} \mathrm{Na-phosphate} \mathrm{buffer}(\mathrm{pH}$ 6.0) containing $0.1 \mathrm{M} \mathrm{NaCl}$. Various derivatives of $\mathrm{Mb}$ were prepared according to Bowen ${ }^{10)}$ with some modifications. Concentration of $\mathrm{Mb}$ was calculated, using the molar extinction coefficient for cyanmetMb at $540 \mathrm{~nm}, 11,300 .{ }^{11}$

Hunter tristimulus values were measured by a color difference meter (Nippon Denshoku Co., ND-1001DP type), and metMb\% by the method reported previously..$^{1,8)}$

*1 Laboratory of Marine Biochemistry, Faculty of Agriculture, The University of Tokyo, Bunkyo, Tokyo 113, Japan (落合芳博, 周 照仁, 渡部終五, 橋本周久: 東京大学農学部水産化学研究室).

*2 Present address: National Kaohsiung Institute of Marine Technology, Kaohsiung 800, R. O.C. 

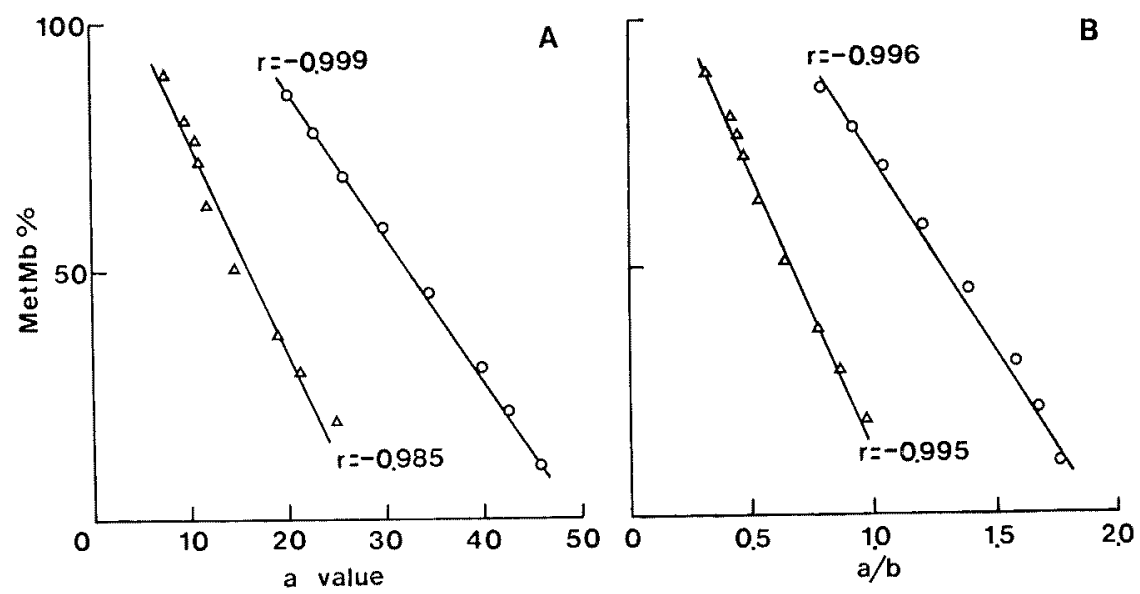

Fig. 1. Effect of $\mathrm{Mb}$ concentration on the correlationship between a value and metMb\% (A) and between $\mathbf{a} / \mathbf{b}$ and metMb $\%$ (B). Mb concentration: $0,1.1 \mathrm{mg} / \mathrm{ml} ; \triangle, 0.7 \mathrm{mg} / \mathrm{m} l$.

\section{Results and Discussion}

The tristimulus values of various derivatives from bluefin tuna $\mathrm{Mb}$ are shown in Table 1. $\mathbf{L}, \mathbf{a}$, and $\mathbf{b}$ values of deoxymyoglobin (deoxy Mb) were $46.4,43.0$ and 12.2 , respectively. When deoxy $\mathrm{Mb}$ was converted into oxy $\mathrm{Mb}, \mathbf{b}$ increased more than two fold, although two other values did not change practically. On the other hand, $\mathbf{a}$ and $\mathbf{b}$ values increased significantly, when deoxyMb was converted into the carbonyl form.

When $\mathrm{Mb}$ autoxidized into the met form, a value sharply decreased to 15.5 , while $\mathbf{L}$ and $\mathbf{b}$ increased to some extent. Especially, $\mathbf{L}$ value in metMb increased up to 57.8 , which was highest among the derivatives assayed. When metMb was further converted into the cyanmet form, $\mathbf{L}$, a and $b$ values changed into $45.2,32.3$, and 26.4 , respectively. As demonstrated here, tristimulus values rather widely changed depending upon the form of $\mathrm{Mb}$, indicating the usefulness of the

Table 1. Color and tristimulus values of bluefin tuna $\mathrm{Mb}$ derivatives. Protein concentration was adjusted to $1.1 \mathrm{mg} / \mathrm{ml}$ in $50 \mathrm{~mm} \mathrm{Na}$-phosphate buffer ( $\mathrm{pH} 6.0$ ) containing $0.1 \mathrm{M} \mathrm{NaCl}$

\begin{tabular}{llccc}
\hline \multirow{2}{*}{ Derivative } & Color & \multicolumn{3}{c}{ Tristimulus values } \\
\cline { 3 - 5 } & & L & a & b \\
\hline DeoxyMb & Magenta & 46.4 & 43.0 & 12.2 \\
OxyMb* & Bright red & 49.7 & 47.6 & 26.4 \\
CarbonylMb & Deep pink & 49.9 & 55.5 & 21.7 \\
MetMb & Brown & 57.8 & 15.5 & 27.7 \\
CyanmetMb & Orange & 45.2 & 32.3 & 26.4 \\
\hline
\end{tabular}

* Contained $13 \%$ metMb.

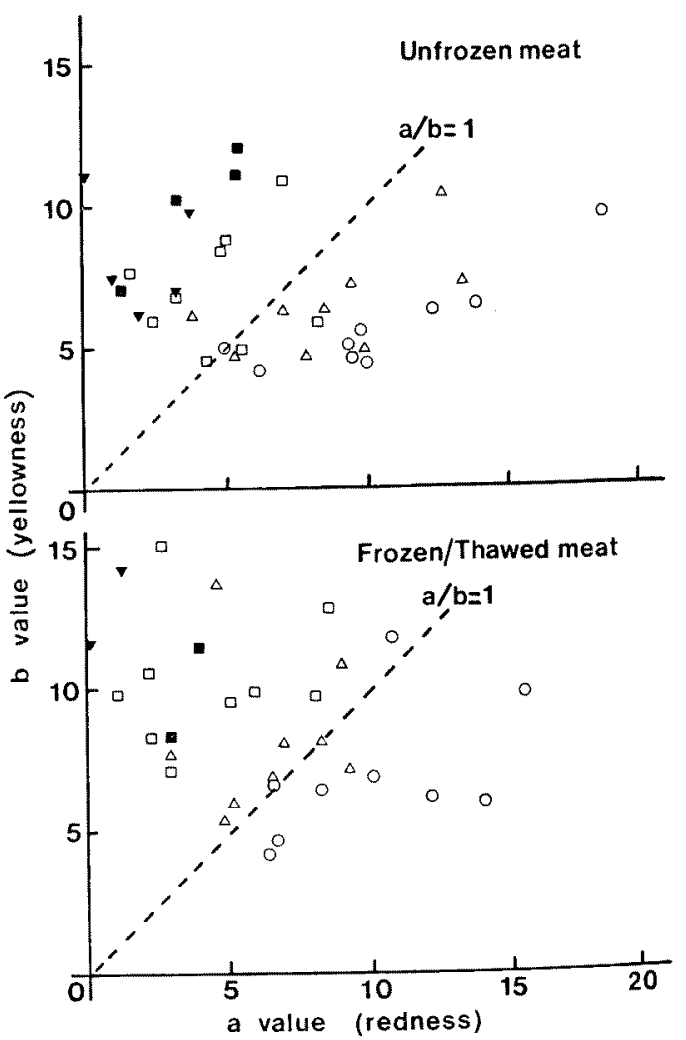

Fig. 2. Plot of $\mathbf{a}$ and $\mathbf{b}$ values in unfrozen or frozen/ thawed bluefin tuna meat which was stored in ice for 0 day $(O), 3-4$ days $(\triangle), 5-7$ days $(\square), 8-10$ days $(\boldsymbol{D})$, and over 11 days $(\nabla)$. The frozen/ thawed samples were prepared by freezing meat slices at $-80^{\circ} \mathrm{C}$ for $2 \mathrm{~h}$, and subsequent thawing at $20^{\circ} \mathrm{C}$. 


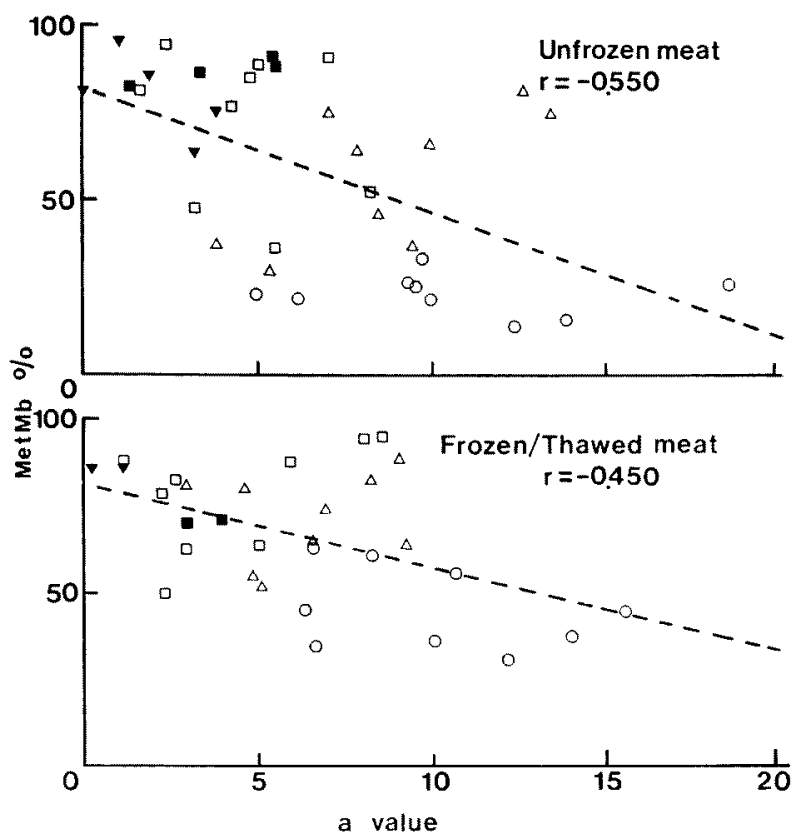

Fig. 3. Correlation between a value and met $\mathrm{Mb} \%$ in unfrozen or frozen/thawed bluefin tuna meat which was stored in ice for 0 day $(0), 3-4$ days $(\triangle), 5-7$ days $(\square), 8-10$ days $(\square)$, and over 11 days $(\boldsymbol{\nabla})$.

colorimetric evaluation for the discoloration of not only tuna $\mathrm{Mb}$ but also tuna meat.

To elucidate correlations between metMb\% and tristimulus values, the time course of $\mathrm{Mb}$ autoxidation was followed as function of these three values. Since the decrease of a value was always accompanied by the increase of metMb\%, a value seemed to be a good parameter to evaluate the autoxidation of $\mathrm{Mb}^{1}{ }^{1)}$ Actually, close correlation was obtained between $a$ value and metMb $\%$, the correlation coefficient ( $\mathrm{r}$ ) being -0.999 at a $\mathrm{Mb}$ concentration of $1.1 \mathrm{mg} / \mathrm{ml}$, and -0.985 at $0.7 \mathrm{mg} / \mathrm{m} l$ (Fig. $1 \mathrm{~A}$ ). When $\mathbf{a} / \mathbf{b}$ was plotted against metMb $\%$, a good correlation was attained again, with $r=-0.996$ at $1.1 \mathrm{mg} / \mathrm{ml}$, and -0.995 at $0.7 \mathrm{mg} / \mathrm{ml}$ (Fig. 1B). On the other hand, correlations between $\mathbf{L}$ value and met $\mathrm{Mb} \%$ and between $b$ value and met $\mathrm{Mb} \%$ were rather low, with $\mathrm{r}=0.648$ and -0.494 , respectively (data not shown). These results suggested that the autoxidation of bluefin tuna $\mathrm{Mb}$ can satisfactorily be evaluated by colorimetry, taking $\mathbf{a}$ value or $\mathbf{a} / \mathbf{b}$ as a parameter.

In the next place, changes in tristimulus values of bluefin tuna meat during iced storage were followed and plotted (Fig. 2). A line of $\mathbf{a} / \mathbf{b}=1$ (broken line) was drawn because this line was considered to be a useful criterion for sensory

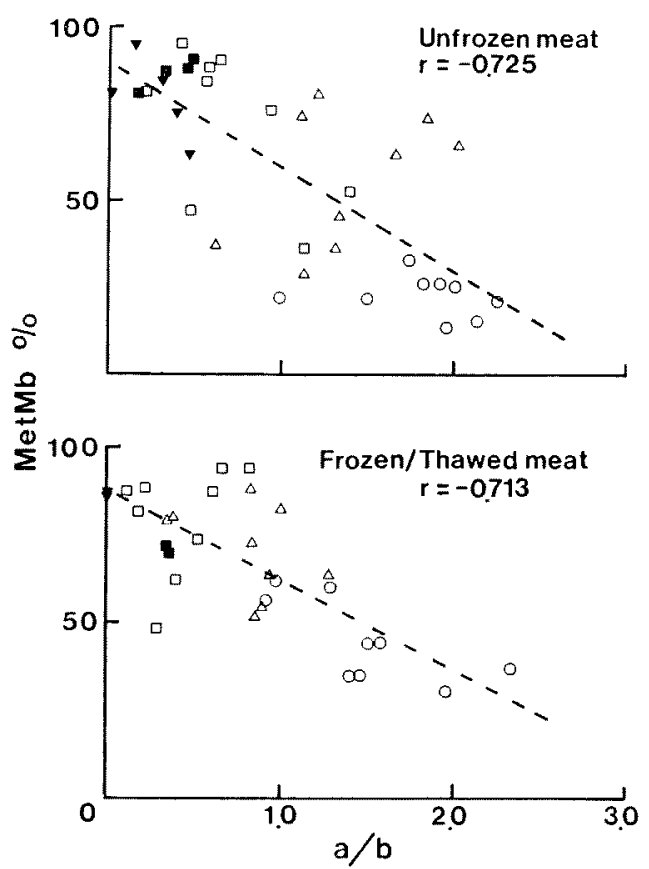

Fig. 4. Correlation between $\mathbf{a} / \mathbf{b}$ value and metMb\% in unfrozen or frozen/thawed bluefin tuna meat which was stored in ice for 0 day (O), 3-4 days $(\triangle), 5-7$ days $(\square), 8-10$ days $(\square)$, and over 11 days $(\boldsymbol{\nabla})$.

evaluation of meat discoloration; i.e., when a 


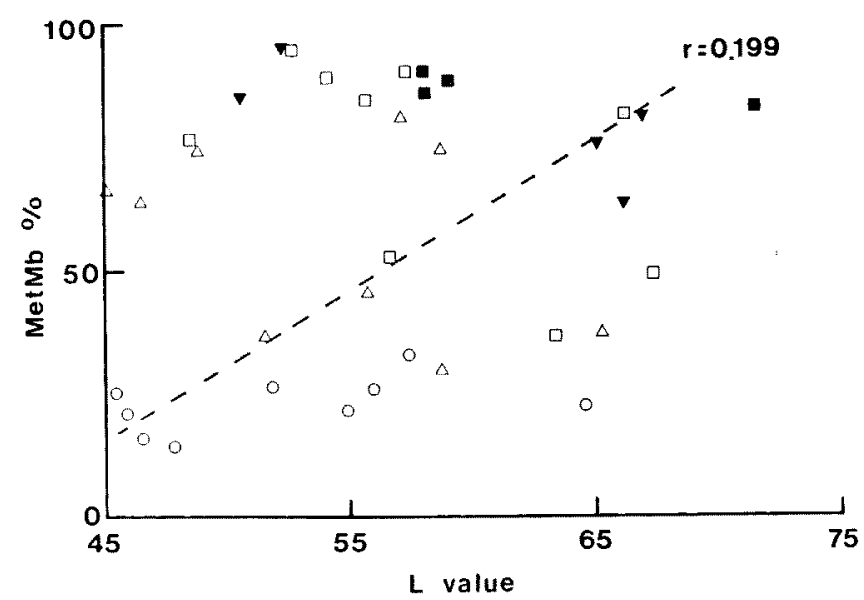

Fig. 5. Correlation between $\mathbf{L}$ value and metMb\% in unfrozen bluefin tuna meat which was stored in ice for 0 day $(O), 3-4$ days $(\triangle), 5-7$ days $(\square), 8-10$ days $(\square)$, and over 11 days $(\nabla)$.

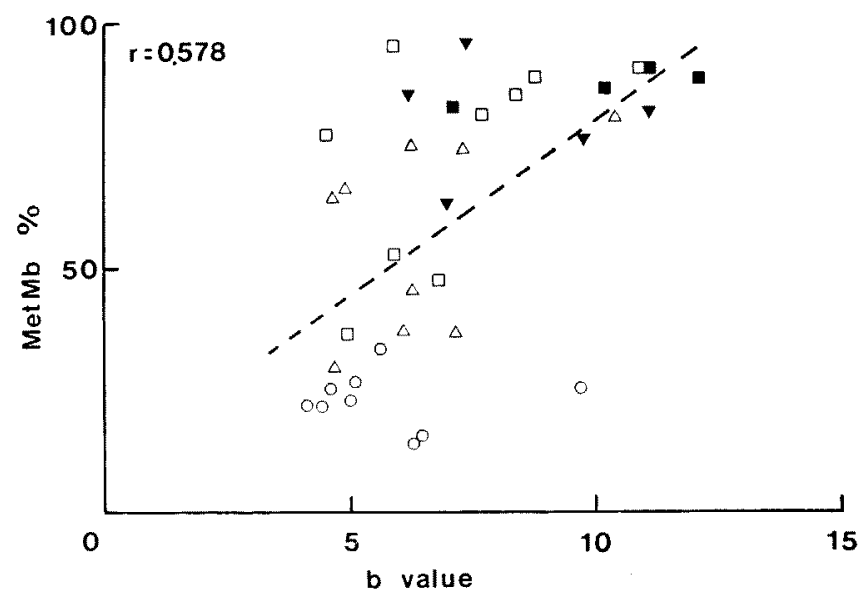

Fig. 6. Correlation between $\mathbf{b}$ value and metMb\% in unfrozen bluefin tuna meat which was stored in ice for 0 day $(0), 3-4$ days $(\triangle), 5-7$ days $(\square), 8-10$ days $(\mathbf{E})$, and over 11 days $(\nabla)$.

point is below this line, the meat is considered to maintain a visually acceptable color. In unfrozen meat, most points were below this line until 4 days of iced storage, whereas in frozen/ thawed meat, many points shifted above the line even within 4 days of storage. These results agreed well with our previous observation that frozen/thawed tuna meat discolored more quickly than unfrozen meat. ${ }^{1}$

Fig. 3 shows the correlation between metMb \% and a value. Increase of metMb\% and the decrease of a value were generally faster in frozen/ thawed meat than in unfrozen one," but the relation between these parameters was not so clear in this figure, $\mathrm{r}$ being -0.550 and -0.450 , respectively. These coefficients were much smaller than those with $\mathrm{Mb}$ solution (Fig. 1). In addi- tion, a value widely varied from a sample to another even after the same period of storage, while metMb $\%$ fell in quite a narrow range.

Correlation between $\mathbf{a} / \mathrm{b}$ and met $\mathrm{Mb} \%$ in bluefin tuna meat are shown in Fig. 4 , because both elements closely correlated in Mb solution (Fig. 1). Increase of metMb\% and decrease of $\mathbf{a} / \mathbf{b}$ ratio were clearly faster in frozen/thawed meat than in unfrozen meat. The correlation coefficients obtained were -0.725 and -0.713 for unfrozen and frozen/thawed meat, respectively, suggesting that $\mathbf{a} / \mathbf{b}$ ratio can be used as parameter to evaluate the discoloration in bluefin tuna meat.

Correlation coefficient between metMb\% and $L$ value was quite low $(r=0.199)$ for unfrozen bluefin tuna meat (Fig. 5), which was much lower than the coefficient with $\mathrm{Mb}$ solution $(r=0.648)$. 


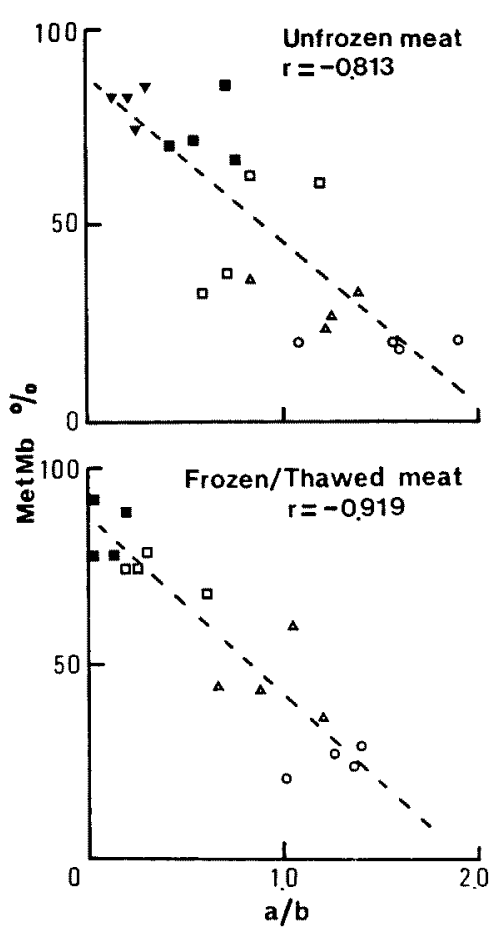

Fig. 7. Correlation between $\mathbf{a} / \mathbf{b}$ and metMb $\%$ in unfrozen or frozen/thawed yellowfin tuna meat which was stored in ice for 0 day $(0), 3-4$ days $(\triangle), 5-7$ days $(\square)$, 8-10 days $(\boldsymbol{m})$, and over 11 days $(\boldsymbol{\nabla})$.

In addition, the correlation coefficient between $\mathbf{b}$ value and metMb\% was 0.578 for unfrozen meat (Fig. 6), which was somewhat higher than that between $\mathbf{a}$ value and metMb\% $(\mathrm{r}=-0.550)$. However, b value was judged to be less useful because of a rather small change associated with discoloration.

Similar investigations were performed on yellowfin tuna meat. Correlation coefficients between metMb $\%$ and $a$ value were -0.672 and -0.843 for unfrozen and frozen/thawed meat, respectively (data not shown). These coefficients were clearly higher than those for bluefin tuna. When a/b ratio was taken as a parameter, the correlation coefficients against met $\mathrm{Mb} \%$ were -0.813 and -0.919 for unfrozen and frozen/thawed meats, respectively (Fig. 7). It follows that $\mathbf{a} / \mathbf{b}$ ratio can be a useful parameter in yellowfin tuna as well. Both $\mathbf{L}$ and $\mathbf{b}$ values were remotely correlated with metMb\% in unfrozen yellowfin tuna meat, with $r=0.445$ and 0.490 , respectively (data not shown). On the other hand, bigeye tuna meat discolored quite slowly during iced storage for 15 days. ${ }^{1)}$ Because changes in $\mathbf{L}$, a and b values hardly occurred (data not shown), colorimetric evaluation was considered to be inappropriate in case of bigeye tuna meat.

Snyder $^{3)}$ suggested that $\mathbf{a} / \mathbf{b}$ is better than $\mathbf{a}$ value as a parameter for evaluation of beef color. The present studies on tuna meat supported his suggestion: $\mathbf{a} / \mathbf{b}$ was more reasonable than $\mathbf{a}$ value, much more than $\mathbf{L}$ and $\mathbf{b}$ values, in unfrozen and frozen/thawed bluefin or yellowfin tuna meat. In this connection, it was noted that most meat samples maintained a favorable red color as long as the ratio was above 1 . Little ${ }^{8)}$ claimed that $\mathbf{L}, \mathbf{a}$, and $\mathbf{b}$ coordinates in the Hunter scale could be a reasonable criterion for the apparent color of food, only if those limitations were thoroughly understood. The present results demonstrated that $\mathbf{a} / \mathbf{b}$ could evaluate quite precisely the discoloration of bluefin and yellowfin tuna meat during storage.

\section{Acknowledgments}

This study was supported in part by a Grant-inAid from the Ministry of Education, Science and Culture of Japan.

\section{References}

1) C.-J. Chow, Y. Ochiai, S. Watabe, and K. Hashimoto: Nippon Suisan Gakkaishi, 54, 639 -648 (1988).

2) R. W. Dean and C. O. Ball: Food Technol., 14(6), 271-286 (1960).

3) H. Snyder: J. Food Sci., 29, 535-539 (1964).

4) R.S. Hunter: J. Opt. Soc. Am., 48, 985-995 (1958).

5) T. Philip, C. W. Weber, and J. W. Berry: Food Technol., 30(11), 58-59 (1976).

6) R.L. Huggart and F.W. Wenzel: Food Technol,, 9(1), 27-29 (1955).

7) R. M. Basel: J. Food Technol., 18, 797-799 (1983).

8) A. C. Little: Food Technol., 30(10), 74-82 (1976).

9) C.-J. Chow, Y. Ochiai, and K. Hashimoto: Nippon Suisan Gakkaishi, 51, 2073-2078 (1985).

10) W. J. Bowen: J. Biol. Chem., 179, 235-245 (1949).

11) D. L. Drabkin: Am. J. Med. Sci., 209, 268-270 (1945). 